\title{
Agricultural expansion, forest products as safety nets, and deforestation
}

\author{
Philippe Delacote * \\ Economics Department, EUI, Florence
}

Villa San Paolo, Via della Piazzuola 43, 50133 Florence, Italy.

\begin{abstract}
Incompleteness of insurance markets is a crucial weakness of developing countries. In this context, the poor households of rural regions often exploit common property resources, such as forests, as insurance in case of economics stress. The aim of this paper is to derive the implications of this insurance use on the forest cover, and thus on deforestation. The land-use choice between agricultural land and forest therefore resembles a portfolio diversification. However, I also show that this insurance strategy may lead to over-exploitation and constitute poverty-trap.
\end{abstract}

Keywords: deforestation; household model; risk aversion; agricultural expansion; forest products.

JEL classification: D13; O12; O13; Q12; Q15; Q23.

*Corresponding author: philippe.delacote@iue.it 


\section{Introduction}

Insurance markets of rural regions in developing countries are often incomplete, if not nonexistent. This situation gives non-conventional insurance systems an important role. Among these systems, common property resources (CPR) appear to have an important insurance role. Several case studies have studied the insurance role of commonly held resources, such as forests, commonly held lands or even fisheries.

A particular activity is often used as a safety net: Non-Timber Forest Products (NTFP) extraction $^{1}$. Populations of interest here are farming communities that rely on forest as a supplementary source of income (Byron and Arnold, 1999). In case of bad agricultural crops, the households extract NTFP from the forest in order to smooth their consumption.

The aim of this paper is to understand the impact of this insurance use of forest products on the land-use choice. Indeed, agricultural expansion appears to be the most important cause of deforestation. The share of deforestation related to agricultural expansion has been estimated at at least 50 per cent (Myers, 1992; UNEP, 1992) and at 70 per cent in the 1990's (UNEP, 2003). In Africa, which is the area with the highest deforestation rates in the world, more than 50 per cent of the deforested zones were switched into small exploitations. Simultaneously, agricultural development is an important tool for poverty alleviation and long term development (World Bank; 2000). The consequences of this insurance role of NTFP extraction on deforestation is thus an interesting issue and can be investigated with farm household models - a priority for future research (Angelsen and Kaimowitz, 1998).

Even if some papers have studied the insurance role of common property resources (Agarwal, 1991 ; Baland and Francois, 2004 ; Pattanayak and Sills, 2001), they do not consider the impact of this insurance role on the land-use decision. However the households face a trade-off between forest and agriculture. Agriculture can be a way to alleviate poverty, but is a risky activity, while NTFP extraction has low poverty alleviation potential, but is a useful tool to compensate for agricultural risk. This paper investigates therefore the impact of the use of NTFP as safety nets on the household's decision to increase their agricultural

\footnotetext{
${ }^{1}$ The term "non-timber forest product" encompasses all biological materials other than timber which are extracted from forests for human use.
} 
land, and thus, to clear forests. This problem is equivalent to a naive portfolio diversification (Francis et al., 1979) between equities -agriculture- and bonds -extraction of NTFP.

Two kinds of insurance strategies can be implemented. The coping strategy consists in extracting NTFP only when agricultural output is too low, working as a "natural" insurance mechanism, while the diversification strategy is closer to a classic portfolio analysis, because the households extract NTFP in all states of the world (Aldermann and Paxson, 1994). Therefore, the problem for the local communities has both the characteristics of portfolio analysis and economics of insurance. The paper stresses a comparison between this coping strategy and a risk-diversification strategy ${ }^{2}$.

To address this issue, we build on Angelsen (1999). Our extension allows for agricultural crops uncertainty and for NTFP extraction, neither of which are considered in Angelsen (1999). Thus the model is an expected utility maximization process of a risk-averse household which uses forest products to face agricultural crops uncertainty. We assume a community that does not have access to insurance nor credit market, so that the safety-net use of forest products is the only way to insure themselves against crop risks.

In the coping-strategy case, our comparative statics show that two opposite effects determine the global impact of forest productivity on the forest cover. The portfolio effect is a relative profitability effect between agriculture and forests: more land is kept as forests if forests provide a lot of NTFP. The insurance effect has the opposite impact: if forests provide a lot of NTFP, less land is needed to insure the households against agricultural crop risks and forest cover is reduced. Moreover, we show that if the two states of the world have the same probability, risk reduction and lower risk aversion lead to less forest cover.

A diversification strategy tends to keep more land as forest, by raising the global value of forest products. Moreover, in this diversification case, higher risk aversion, higher forest productivity and a smaller population always tend to have a positive impact on the forest cover.

Finally, Angelsen and Wunder (2003) notes that this activity can constitute a poverty trap for poorer households. Thus determining the conditions under which a CPR constitutes both a safety net and a poverty trap is also an important issue. I define a poverty trap as a situation in which households cannot get more than their subsistence requirement from

\footnotetext{
${ }^{2}$ The strategies are studied as given and the choice process of the strategy is not considered.
} 
their activities. In the case considered here, households are "trapped" in CPR extraction activity because of their need of insurance, which keeps them away from other development opportunities. CPR extraction can constitute a poverty trap as a result of a tragedy-of-thecommons process. Too much people are in need of insurance and the resource cannot provide enough to properly insure all the population. They face thus the classic poverty-environment vicious circle, where poor people depends too much of their environment and overuse it.

Section 2 gives a brief review of the literature, emphasizing the use of NTFP for poor agricultural households, describing the economics of land-use in agricultural areas and the insurance properties of common property resources. Section 3 presents a household model of land-use choice with risk on agricultural output and NTFP extraction used as safety net. Section 4 shows how a CPR can constitute both a safety net and a poverty trap. Finally section 5 concludes and discusses the policy implications.

\section{Review of the literature}

\subsection{The use of non-timber forest products}

Poverty and environmental degradation are often said to constitute a vicious circle (SARDC, IUCN and SADC 1994 in GEO 2000, Chapter 2). Poor people are dependent on the environment, and thus overuse it, which makes them even poorer. The Brundtland report (1987), the first to underline the importance of poverty in environmental degradation, was followed by the 1992 Rio conference. The implicit conclusion of this link is a win-win potential of helping poor countries to develop and to protect the environment at the same time. Concerning the deforestation process, this vicious circle analysis appears to be appropriate, given that poor households are the main agents of deforestation. In Africa, this link appears to be related to the low productivity and input use of smallholder agriculture, which leads to land degradation and agricultural expansion (Reardon et al., 1999).

More than 1.6 billion people depend to varying degrees on forests for their livelihood. About 60 million indigenous people are almost wholly dependent on forests. Some 350 million people who live within or adjacent to dense forests depend on them to a high degree for subsistence and income. In developing countries, about 1.2 billion people rely on agro- 
forestry farming systems that help to sustain agricultural productivity and generate income. Worldwide, forest industry provides employment for 60 million people. Some 1 billion people depend on drugs derived from forest plants for their medical needs (World Bank, 2001). Disregarding the problem of having defined precisely the concept of forest dependency (see Wollenberg and Ingles, 1998), it appears that forest-dependent people, who are poor for the most important part, constitute a real challenge to development and environment.

Different strategies of the use of forest products can be elaborated by the households, depending essentially on their market integration. A typology of these strategies is provided by Angelsen and Wunder (2002). First, the specialized strategy, related to a high integration into markets, gives the forest products a high contribution to income - this strategy fits with the Asia case. Second, the diversification strategy, also related to a high integration into markets, only gives a marginal share of income to the forest products - this is the case for Latin America. Third, the coping strategy is associated with a low share of income from forest products and a low integration into markets. This last strategy does not imply, however, that households do not depend on forest, since they may use forest resources for direct consumption. The coping strategy is often seen in Africa.

The first strategy allows an explicit important contribution of NTFP to income, with extraction being a main activity of the household. In contrast, the last two strategies give NTFP extraction a risk-management role: a relatively low importance in terms of income, but a useful tool to smooth household consumption.

The safety-net use of NTFP: The diversification strategy is a classic risk-management tool (Aldermann and Paxson, 1994). The household raises ex ante the number of its activities, choosing if possible activities that have low covariance.

In contrast, the coping strategy consists in extracting NTFP only in the case of bad agricultural crops. The use of NTFP can here be considered as an ex post gap filling use. Forest products are extracted in order to smooth the household's consumption in case of low crop returns. Indeed, agricultural crops being quite uncertain, NTFP can be used as a complement in the case of unpredicted shortfalls. This typical use of NTFP represents a risk-coping strategy (Aldermann and Paxson, 1994) of the household, that is a strategy that deals with the consequences of income risk. These two uses can be particularly important in 
the case of common risk, because intra-village credit or insurance systems are more difficult to implement (Dercon, 2002).

The insurance role of forest products is particularly important in the rural systems of developing countries, given that agricultural crops face many risks, such as price shocks, seasonal flooding, unpredictable soil quality, pests, crop diseases or illnesses. NTFP can be used directly in consumption or sold to fill cash gaps. Formally, rural households, which have limited credit and insurance options, choose a diversification of their activities (thus of the land), in order to reduce aggregate risk (Morduch, 1995; Godoy et al., 1998). Some studies analyze this use of NTFP (Baland and Francois, 2004; Pattanayak and Sills, 2001). One of the results is that any individual is more likely to visit the forest if the crops are more risky or if he faces a negative shock. Godoy et al. (2000), in a study in Honduras, argue that although NTFP extraction has a low annual value, it can provide insurance in the case of unexpected losses.

In these two risk-management approaches, NTFP extraction appears to be efficient for poor rural households. First, a large variety of NTFP can be extracted, thus raising the diversification of activities. In most developing countries, households collect dead timber to be used as fuel. Chopra et al. (1999) note that, in rural India, forests are almost the exclusive source of fuel, fodder and fibres for very poor households. Another study in rural India mentioned oil seeds, edible fruits, staple foods, vegetables, spices, rope, leaf-plates and medicinal plants as NTFP used by households (Kumar, 2002). In the Tapajos National Forest (Brazilian Amazon), forests provide vines, honey, sap, Brazilian nuts, fruits bark and rubber (Pattanayak and Sills, 2001). Second, many NTFP do not have strong positive correlation among themselves or with agriculture (Pattayanak and Sills, 2001), so that they can be efficient risk-management instruments. A bad agricultural output is not necessarily linked to bad forest product quantities.

Two characteristics of NTFP are important to note. First, there are low capital and skills requirements for NTFP extraction as well as open or semi-open access to the resource, so that poor households can easily extract the resource. Indeed, Neumann and Hirsch (2000) argue that the poorest people are those who are most engaged in NTFP extraction. Second, NTFP habitually have a low return to labor, so that they have poor potential to alleviate poverty (Wunder, 2001; Angelsen and Wunder, 2002). These two characteristics raise the 
question of NTFP as safety nets or poverty traps. On the one hand, NTFP can be considered as safety nets, as there is a lack of better alternatives for households, and NTFP provide some food security (considered in section 3). On the other hand, the implication of NTFP extraction can be a poverty trap, because of the low development potential of these products (see section 4). Table 1 gives an example of the share of NTFP extraction in the total income, and its relation between the level of income and NTFP extraction. It gives an illustration of the relatively low share of NTFP in total income -which argues for the risk-management strategies- and of the link between poverty and NTFP use.

Table 1: Relation between level of income (CFA) and the share of NTFP sales for Bagyeli and Bantu people in South Cameroon

\begin{tabular}{|c|c|c|c|c|c|}
\hline $\begin{array}{c}\text { NTFP as } \% \\
\text { of income }\end{array}$ & $\begin{array}{c}\text { Income } \\
<5000\end{array}$ & $\begin{array}{c}\text { Income } \\
5000-50000\end{array}$ & $\begin{array}{c}\text { Income } \\
50000-100000\end{array}$ & $\begin{array}{c}\text { Income } \\
>100000\end{array}$ & Total \\
\hline$<5 \%$ & $45-13$ & $14-13$ & $8-10$ & $5-3$ & $72-38$ \\
$5-25 \%$ & $0-0$ & $7-11$ & $5-3$ & $0-7$ & $12-21$ \\
$25-50 \%$ & $2-2$ & $3-10$ & $1-3$ & $0-2$ & $7-16$ \\
$>50 \%$ & $6-13$ & $3-11$ & $0-2$ & $0-1$ & $9-26$ \\
Total & $53-27$ & $28-44$ & $14-17$ & $5-13$ & $100-100$ \\
\hline
\end{tabular}

$X-Y \%=\%$ surveyed population in Bagyeli and Bantu respectively.

Source: Van Dijk, in Ros-Tonen and Wiersum (2003)

Hence, forests are competing for land-use, with agricultural use representing the most important alternative. Indeed, forest products have a low potential of poverty alleviation, but can be used to compensate shortfalls in agricultural yields. Conversely, agricultural crops can be a way out of poverty for households, but may represent a high level of risk, especially if the households are poorly integrated into markets. The trade-off between these two land-uses is a major choice for poor rural households, and is a potentially driving force of deforestation. An interesting topic is thus to analyze the land-use choice process of the households. 


\subsection{Earlier studies on land-use choice}

This process has already been treated analytically and empirically in the literature. Two main dimensions have to be taken into account. The first is the degree of market integration. One possibility is a subsistence economy, where households do not have any access to markets and whose objective is to reach a subsistence level of consumption (Angelsen, 1999). The opposite case is where households are perfectly integrated into markets (Angelsen, 1995, 1999 ; Parks et al., 1998). Here the separability assumption (Lopez, 1986) applies, where households decide independently their production decision, through profit maximization, and their consumption decision. In practice, households may be imperfectly integrated in some markets (Angelsen, 1999; Bluffstone, 1995; Barbier, 2000; Hartwick et al., 2001, Lopez, 1998) which affect the separability assumption. In that case, households maximize their utility subject to budget constraints. In our framework, market integration is particularly important, as it can create other potential insurances: off-farm opportunities, and credit and insurance markets.

The second dimension taken into account is the definition of the property rights institutions. Property may be private, in which case land rent is the major factor affecting land-use (Angelsen, 1999; Hartwick et al., 2001; Parks et al., 1998; Vosti et al, 2003). However, forests can also be common-property (Lopez, 1998), which is shared private property rights (Ostrom, 2000). In that case, a precise study of land management is needed. Another possibility is open access to the land (Bluffstone, 1995). Here a crucial point is the possible assignment of property rights through forest clearing. Indeed, in some developing countries, forest clearing may de facto create permanent land rights (Angelsen, 1995, 1999). In developing countries, the state owns about 80 per cent of the forests (Angelsen, 1995). In fact, most governments do not have many control nor coercive capacities, and land is in fact open access. In that case, this particular type of property rights may be an incentive to deforestation. In this paper, the safety-net use of NTFP implies that forest area is open-access or managed common property, such that the households can enter the forest and extract NTFP.

Among the papers that study land-use choice by rural communities, only a few take into account forest product use, and none study the safety-net use described here. Lopez (1998) notes the coexistence in most developing countries of private lands, intended for agricultural 
crops, and common property lands, namely forests, used for their products. In his paper, however, the two land-uses compete with each other and forest products do not have the gap filling function. Specifically, Lopez analyzes the consequences of agricultural intensification and farm productivity improvement programs on the pressures on the common resource. The main factor determining the programs' impact on pressure on the common resource is the factor-intensity of the crops. If crops are labor-intensive, then a rise in their prices is likely to diminish the pressure on the common resource. However, if crops are land-intensive, the pressure is likely to rise with the commodity prices.

Parks et al. (1998) study the competing land-uses, mainly agriculture, timber and nontimber forest products. The paper distinguishes four cases, depending on the relative productivity of the different activities: joint management of forests, forest preservation, conversion to non-forest use, and forest abandonment. These four cases depend mainly on the impact of the age of the trees and the management effort on a profit maximization function. Vosti et al. (2003) study the case of competing land-use between timber harvesting and agriculture. In their paper, giving the households the right to harvest timber improves their income but does not change the land-use much. In fact, costly monitoring controls seem to be established in order to enforce a sustainable harvest. Hartwick et al. (2001) find a cyclical process. First, the driving factor of forest clearing is the agricultural land price. Then, the profit of marketing timber is the most important factor.

\subsection{Common property resources as insurance}

The literature on land-use choice discussed above ignores the insurance role that forests have when they are commonly held. Another part of the literature does, however, argue the importance of common property resources (CPR) as insurance. Comparing the insurance properties of a CPR with the greater efficiency of the privatized resource, Baland and Francois (2004) find a negative impact of land privatization on the social welfare of a community. CPR represent for low skilled households a potential outside option to private projects, since CPR extraction often requires low skilled labor. Therefore, return to the labor allocated to the CPR are homogeneous. The insurance property of the commons follows from the linking 
between labor allocation and resource rent. Indeed, the less skilled people allocate more labor to the CPR, and therefore get a bigger share of the resource rent.

Pattanayak and Sills (2001) find that NTFP collection is positively correlated with agricultural shortfall and expected agricultural risk, which sustain both coping and diversification strategies. According to Bromley and Chavas (1989), non-exclusive property rights can be seen as an integral part of risk sharing. In this case, the common forest can be considered as an asset of last resort (Baland and Francois, 2004). A strong link between poor people and CPR is often underlined. Dasgupta and Maler (1993) argue that local commons provide the rural poor with partial protection in time of unusual economic stress. A study of tribal groups in rural Bihar qualifies communally-held forests as the only means of survival for poorer members in lean seasons (Agrawal, 1991). Reddy and Chahravaty (1999) observe in India a more intensive use of the CPR by poor households. Dasgupta (1987) notes a higher level of CPR products in low labor productivity regions. Johda (1986) finds a negative relationship between CPR income and rural inequalities.

Although some papers study the competing land-use relationship between agriculture and forests, none of them investigate the safety-net use of forest products to insure against crops risk. In contrast, papers studying the insurance role of CPR treat the share private/common land as exogenous. The aim of this paper is thus to reconcile these two sides of the literature, investigating the role of the safety net use of NTFP on the land-use choice.

\section{Coping strategy, risk-aversion and household's opti- mal land-use}

The model presented is an adaptation from Angelsen (1999). In contrast to Angelsen's setup, agricultural output is uncertain and forest provides NTFP that can be used to smooth the household's consumption when the agricultural output is bad.

The set-up for the land : The model represents a village economy. The total area of the village is normalized to 1 . We assume here only two possible uses for the land: agriculture

and forests. Both agricultural and forested areas are assumed to have the same quality. In contrast to Angelsen (1999), we assume here that the forests provide Non-Timber Forest 
Products (NTFP). We assume here for simplicity an egalitarian repartition of the land across the households in the village. Therefore, we consider a representative household, which has a share $\frac{1}{N}$ of the total area of the village ( $\mathrm{N}$ is the number of households in the village and is our indicator of population pressure), which is equivalent to a share $\frac{1}{N}$ of total forest product extraction. We avoid thus the problem of tragedy of the commons, i.e competition between households for the forest products. This assumption is very strong and, in practice, rarely observed. The next section considers the possible competition between households in NTFP extraction, that could lead to a poverty trap through a tragedy of the commons. We also assume that both the agricultural good and the forest product are homogenous. Both goods use land and labor as the only inputs.

$\mathrm{R}$ is the share of agricultural land in the village area $(0 \leq R \leq 1)$. Agricultural land area used by the household is thus defined as $\frac{R}{N}$ and forest land area for household use is $\frac{1-R}{N}$. R is an indicator of the forest cover and the choice variable of the household. At the beginning of the period, the household chooses the share of the land it will cultivate. If $R=1$, all the land around the village is converted to agriculture and deforestation is maximized in the village area. If $R=0$, forest conservation is maximized and there is no agriculture. Between these two extreme cases, there is a trade-off between the two possible uses of the land.

The gap filling use of forest products: We assume that agricultural land is, on average, more productive than forest land, but agricultural production is more volatile than NTFP. Thus, there is a trade-off between a relatively more profitable but riskier activity - agriculture - and a relatively less profitable but safer activity - NTFP extraction. We focus here on the coping strategy. Therefore, we assume that NTFP extraction only happens if the agricultural crop output is low. ${ }^{3}$

In contrast to Angelsen (1999), the agricultural output is not certain. The risk on agricultural crops is supposed to be systemic. Therefore every household in the village lives in the same state of the world. Thus there cannot be inter-household insurance.

There are two states of the world. In the good state, which occurs with probability $\delta$, the agricultural output per hectare is high (or per unit of land, as the area is normalized to

\footnotetext{
${ }^{3}$ Appendix B provides a diversification setting, in which the household extracts NTFP in each state of the world.
} 
1) and the household does not need to extract NTFP.

$$
\bar{C} \equiv \frac{R}{N} \bar{x}
$$

where $\bar{x}$ is the optimal agricultural output per hectare in the good state of the world. We assume that the household uses an optimal combination of labor in the production process. We can therefore forget the labor side for the moment.

In the bad state, with probability $(1-\delta)$, agricultural output is low and the household extracts forest products in order to smooth its consumption.

$$
\underline{C} \equiv \frac{1}{N}[R \underline{x}+(1-R) f]
$$

Here $\underline{x}$ is the optimal agricultural output in the bad state of the world. Clearly $\underline{x}<\bar{x}$ must hold. In this case, the household extracts forest products in order to smooth its consumption. $\mathrm{f}$ is the quantity of forest products per hectare. In contrast to the agricultural output, $\mathrm{f}$ is assumed to be certain.

Expected agricultural output per hectare is therefore:

$$
E(x)=\delta \bar{x}+(1-\delta) \underline{x}
$$

Clearly, by assumption $\mathrm{f}<\mathrm{E}(\mathrm{x})$, for otherwise there is no trade-off between the two land-uses and all the land is used for forest product extraction.

\subsection{Expected utility maximization}

The objective of the household is to maximize its expected utility, given fixed labor supply. Then the household's utility function only depends on consumption: $U=U(C)$, with $\frac{\partial U}{\partial C}>0$. Expected utility is then:

$$
E(U)=E_{U}\left(E_{c} ; \sigma_{c}^{2}\right)
$$

The expected level of consumption of the household is $E_{c}$ and its variance is $\sigma_{c}^{2}$. We have $\frac{\partial E_{U}}{\partial E_{c}}>0$ and $\frac{\partial E_{U}}{\partial \sigma_{c}^{2}}<0$. If we do not specify the utility function, the expected utility is likely to depend on the other moments. We do not consider, however, the case here. This framework is thus consistent with a quadratic utility function or with a CARA function.

We introduce thus a Constant Absolute Risk Aversion (CARA) function:

$$
U(C)=-\exp [-\alpha C]
$$


where $\alpha$ is the Arrow-Pratt Absolute Risk Aversion coefficient.

Mean-variance analysis: Both the expected level of consumption and its variance depend on the share of agricultural land, R, to be chosen by the household. The household can only consume what it produces because it is not integrated into the markets. An equivalent interpretation is to consider the equality between consumption and production as a budget constraint.

Expected utility is then :

$$
E_{U}=-\delta \exp [-\alpha \bar{C}]-(1-\delta) \exp [-\alpha \underline{C}]
$$

where expected consumption and variance do not appear explicitly. The expected level of consumption is:

$$
E_{c}(R) \equiv \delta \bar{C}+(1-\delta) \underline{C}=\frac{1}{N}[R(E(x)-E(f))+E(f)] ; \quad \frac{\partial E_{c}(R)}{\partial R}>0
$$

Expected consumption rises with the share of agricultural land, R, since expected agricultural production is more efficient than forest product extraction. Therefore, a risk-neutral household would convert all the land into fields $(R=1)$ in order to maximize its expected consumption.

Figure 1 compares the relationship between expected consumption and the share of agricultural land for three different strategies. The first strategy is a benchmark that stresses the expected consumption of the household if it does not extract NTFP. The second is the coping strategy, in which NTFP are extracted only in the bad state of the world. The third is the diversification strategy, in which the household extracts NTFP in each state of the world. The use of NTFP as a coping strategy raises expected consumption, because it raises consumption in the bad state of the world. The increase in expected consumption is higher in the diversification case, since NTFP are extracted in both states of the world.

The variance of consumption is:

$$
\sigma_{c}^{2} \equiv E\left(C^{2}\right)-E(C)^{2}=\left(\frac{1}{N}\right)^{2}\left[R \sigma_{x}-(1-R) \sigma_{f}\right]^{2}
$$


Figure 1: The impact of the land-use choice on expected consumption

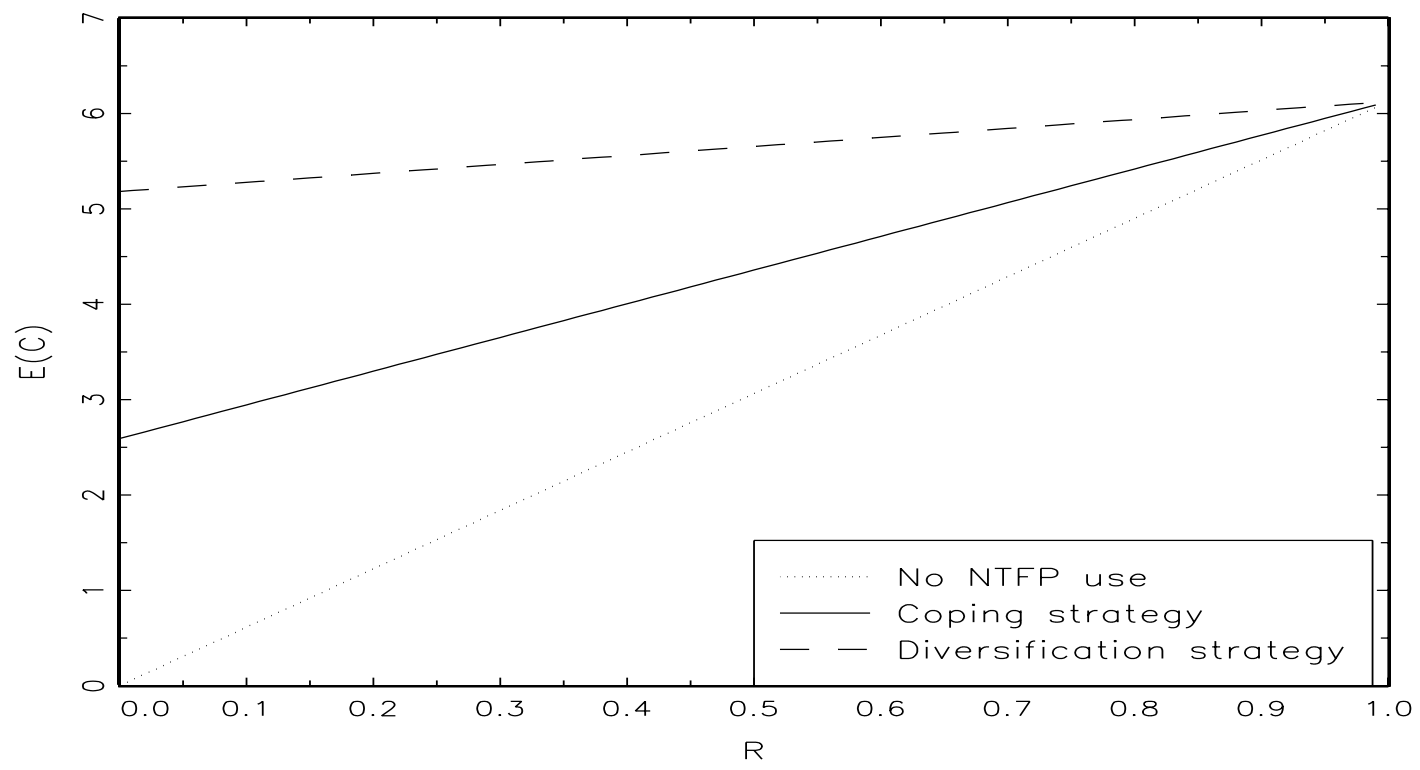

Parameters: App.C.

The variance analysis is less straightforward. ${ }^{4}$ The variance of consumption is minimized (as $\sigma_{c}^{2}$ is a convex function of $\mathrm{R}$ ) and zero if:

$$
R=\frac{\sigma_{f} \sigma_{x}+\sigma_{f}^{2}}{\sigma_{x}^{2}+\sigma_{f}^{2}+2 \sigma_{f} \sigma_{x}} \equiv \underline{R}
$$

If NTFP extraction is impossible, the only way to have no variance in consumption is to have $R=0$, with $E_{c}(R)=0$. With the introduction of NTFP extraction as a coping strategy, it is now possible to have a positive expected consumption with no variance. $\underline{R}$ is thus a lower bound for $\mathrm{R}$, in the coping-strategy case. Indeed, for $R<\underline{R}$, expected utility is increasing in $\mathrm{R}$. In contrast, diversification does not change the relationship between the variance of consumption and $R$, but having a positive expected consumption with no variance is possible, fixing $R=1$. Figure 2 presents the variance of consumption as a function of the share of agricultural land, for each strategy.

The household is clearly better off with NTFP extraction. Its expected level of consumption increases and there can be no uncertainty about the level of consumption. Moreover,

\footnotetext{
${ }^{4}$ In the diversification case, the variance of consumption is always positively correlated with R. See appendix B.1.
} 
Figure 2: The impact of $\mathbf{R}$ on the variance of consumption

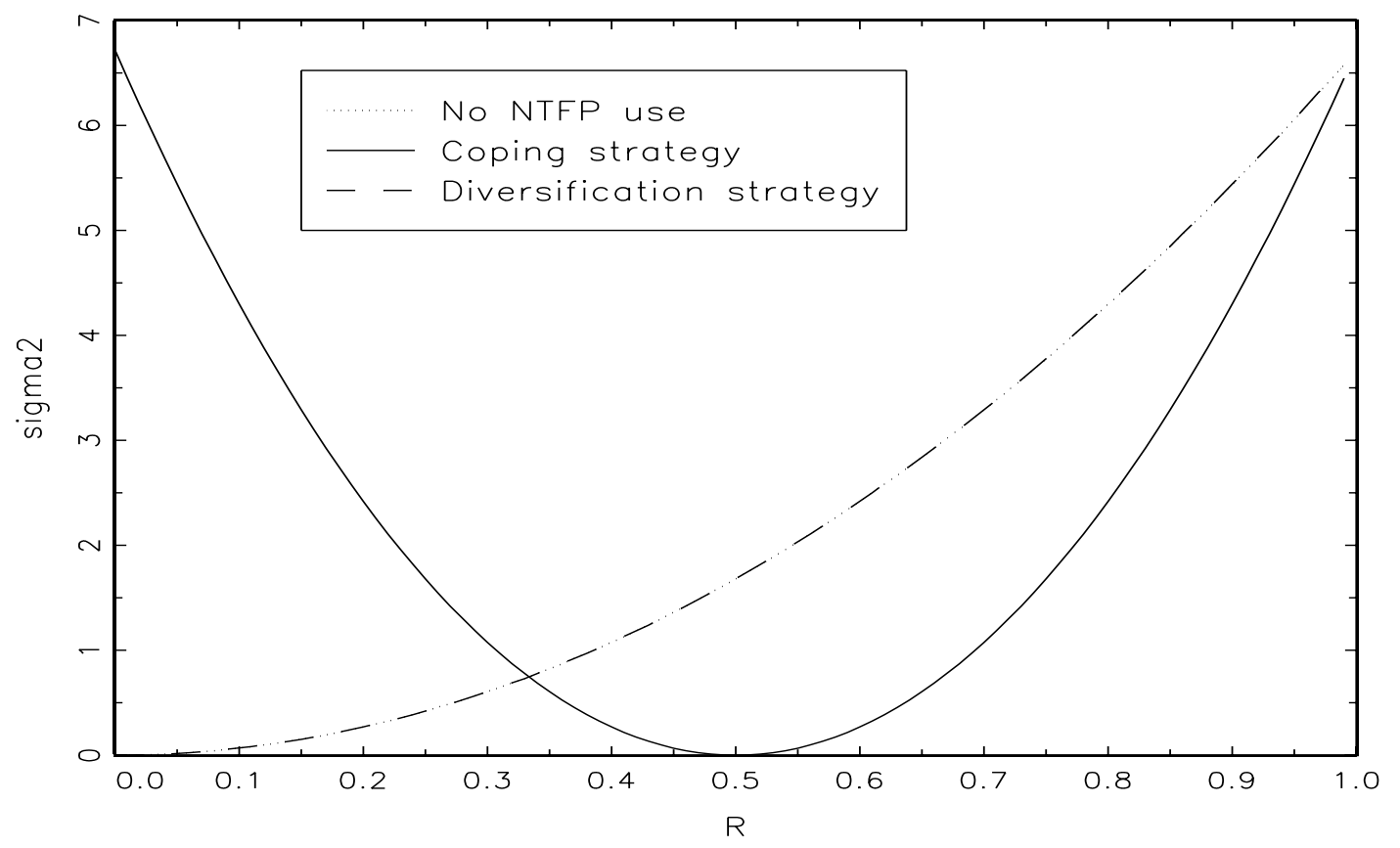

Parameters: App.C.

the diversification strategy is more welfare improving than the coping strategy, as it raises the households' utility in each state of the world (see figure 3). This fact raises the question on the motivations that lead a household to apply the coping strategy instead of the diversification strategy ${ }^{5}$. However, this paper consider the coping strategy as given, without considering the motivations behind it.

This choice in the land-use is a trade-off between expected consumption and variance of consumption. The relative weight given to the expected consumption and the variance will depend on its risk-aversion: a risk-averse household gives more importance to the variance of consumption, than a risk-neutral household. Figure 4 presents the potential couples $\left(E_{c} ; \sigma_{c}^{2}\right)$.

\footnotetext{
${ }^{5}$ Possible explanations: labor allocation, labor/leisure arbitrage, difference in utility between the NTFP and the agricultural good.
} 
Figure 3: Expected utility as a function of $\mathbf{R}$

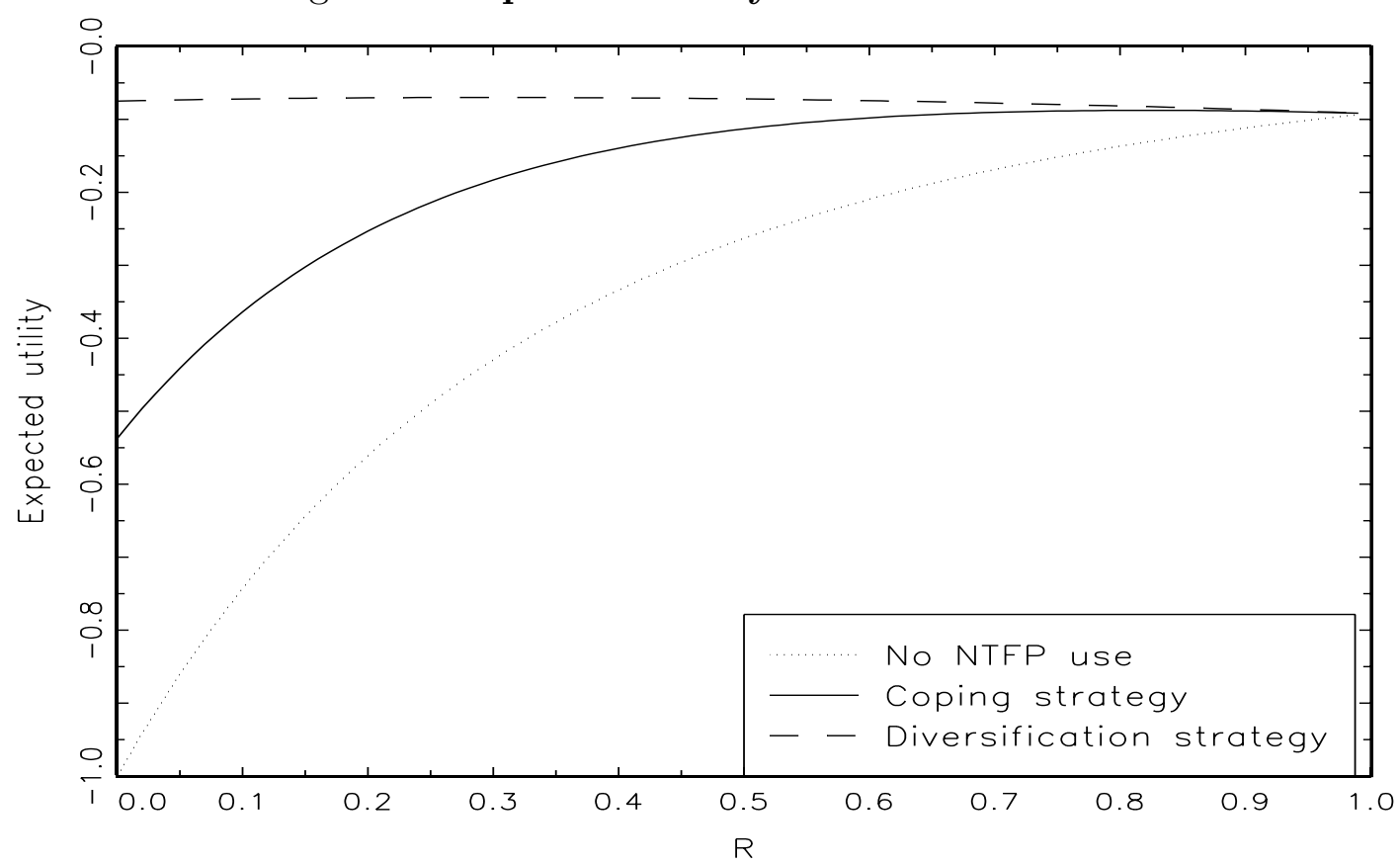

Parameters: App.C.

Figure 4: Possible couples $\left(E_{c} ; \sigma_{c}^{2}\right)$

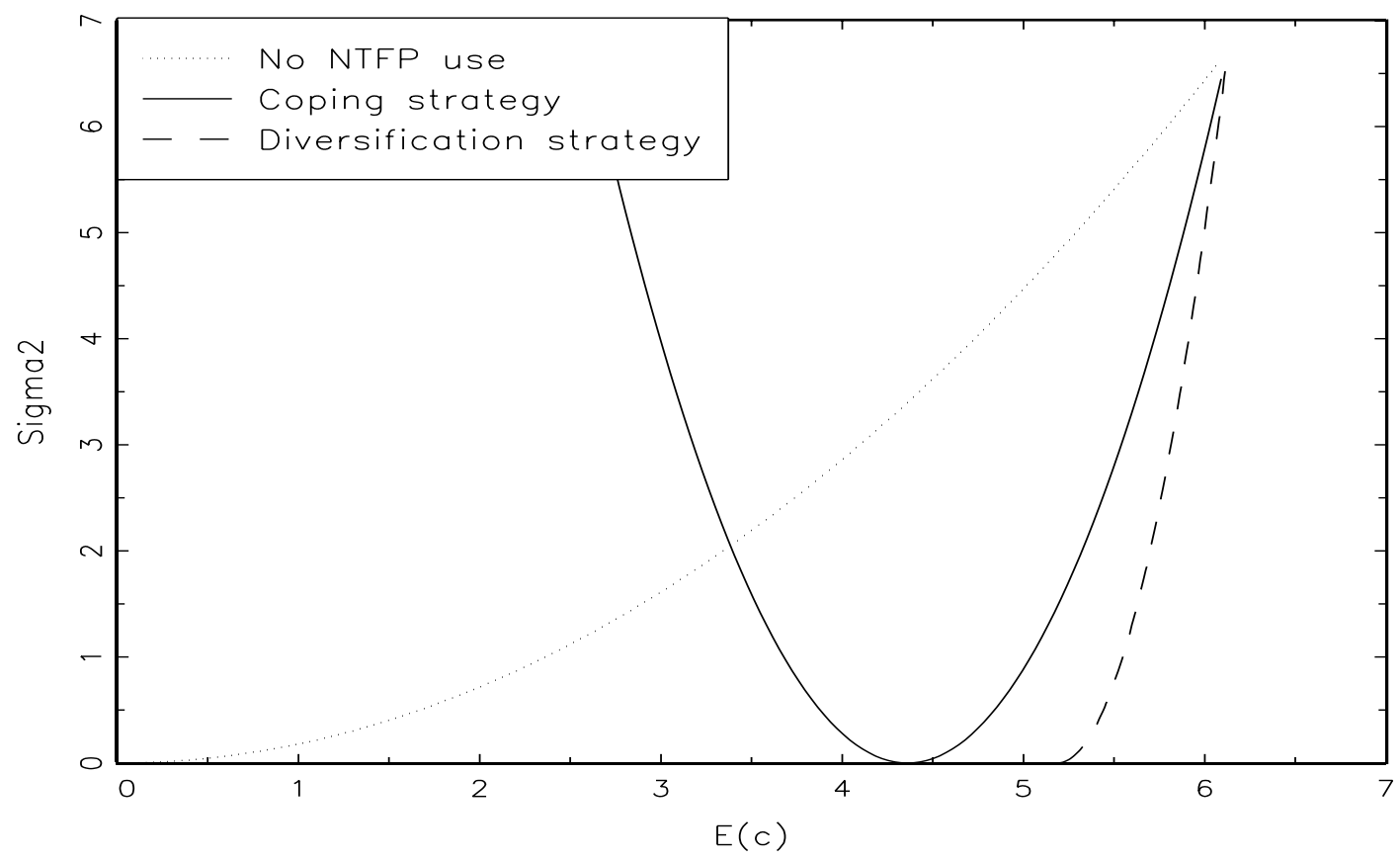

Parameters: App.C. 
Household's objective and the optimal trade-off: The objective of the household is to choose $\mathrm{R}$ in order to maximize expected utility:

$$
\max _{R} E_{U}\left(E_{c}(R), \sigma_{c}^{2}(R)\right)
$$

The household chooses the agricultural frontier to equalize the marginal rate of substitution between the two states of the world and the fraction of the relative productivity of agricultural land (as $f=0$ in the first state of the world) in the two states of the world :

$$
\frac{-\delta \frac{\partial U(\bar{C})}{\partial R}}{(1-\delta) \frac{\partial U(\underline{C})}{\partial R}}=\frac{\underline{x}-f}{\bar{x}}
$$

Note that $\frac{\partial E_{U}}{\partial R}>0$ if $f \leq \underline{x}$. Therefore, we have a corner solution $(R=1)$ if the forest productivity is lower than or equal to the agricultural productivity in the bad state of the world. In this framework, the safety-net use of the forest products only exists if the risk on agricultural output is so high that NTFP extraction becomes the main activity of the household in the bad state of the world. This condition is consistent with a portfolio analysis, where the risk-free asset needs to be more profitable than the risky asset in some states of the world to have a positive share in the portfolio (Gollier, 2001).

We now characterize the agricultural frontier that maximizes expected utility. Plugging (6) in (10) and solving for R, we get the optimal agricultural frontier :

$$
R^{*}=\left(\frac{f+\frac{N}{\alpha}\left[\ln \frac{\delta \bar{x}}{(1-\delta)(f-\underline{x})}\right]}{\bar{x}-\underline{x}+f}\right)
$$

\subsection{Comparative statics}

The comparative statics depend on the value of the parameters $\delta, \underline{x}, \bar{x}$ and $\mathrm{f}$. If we assume that the probability of the good state is 50 per cent $(\delta=0.5)$, we have the following proposition.

Proposition 1 : If both states of the world have the same probability, a risk reduction, a lower risk aversion and a larger population decrease the forest cover.

Proof : sign of the first derivatives of $R^{*}$, for $\delta=0.5$ (see appendix A): $\quad \frac{\partial R^{*}}{\partial \underline{x}}-\frac{\partial R^{*}}{\partial \bar{x}}>0$, $\frac{\partial R^{*}}{\partial \alpha}<0$ and $\quad \frac{\partial R^{*}}{\partial N}>0$. 
In this framework of risk on agricultural output, we define risk reduction as a rise in $\underline{x}$ and a fall in $\bar{x}$, with a constant expected output $E(x)$. This kind of risk reduction can be viewed as the introduction of an insurance system. On the one hand, the household pays a risk premium $d \bar{x}$ per hectare in the good state of the world. On the other hand, if the bad state of the world occurs, the household receives as an insurance $d \underline{x}$ per hectare. ${ }^{6}$ With $\delta=0.5$, this risk reduction definition implies $d \underline{x}=-d \bar{x}>0$. In that case, risk reduction has a positive impact on R. Hence, if the agricultural risk is reduced, the safety-net use of NTFP is less important, agricultural land increases and forest cover declines. Intuitively, if the more profitable activity becomes less risky - with the same expected productivity -, its share in the agent portfolio raises. In our example, the introduction of an insurance mechanism can thus lead to more deforestation.

The impact of risk aversion of the household on the forest cover also depends on the value of the parameters. With $\delta=0.5$, the Arrow-Pratt Absolute Risk Aversion coefficient has a positive impact on the forest cover. Intuitively, if the household is risk averse, it will keep more land as forest in order to insure itself against crop risks, even if this is done at the expense of lower expected consumption. However, this impact is the reverse if $\delta$ is very low, namely $\delta<\frac{f-\underline{x}}{\bar{x}-\underline{x}+f} .7$ Indeed, in this case, NTFP extraction is the main activity of the household more frequently (i.e. in the bad states of the world), but does not take place in the good states of the world. A highly risk-averse household will therefore keep more agricultural land to insure some consumption if the good state of the world occurs.

The conditions of the impact of the population pressure $\mathrm{N}$ are the exact reverse of the ones of the coefficient of risk aversion. If the bad state of the world is very likely, the village population will have a negative impact on the forest cover (positive impact on R). ${ }^{8}$

It is not possible to determine the sign of the impact of the forest productivity ${ }^{9}$ and two opposite effects of this productivity can affect the households' land-use choice.

\footnotetext{
${ }^{6}$ We assume here no principal-agent problem.

${ }^{7}$ The impact of $\alpha$ is always positive in the diversification case.

${ }^{8}$ In the diversification case, a higher population always has a negative impact on the forest cover.

${ }^{9}$ In the risk diversification case, the forest productivity is always positively correlated to the forest cover. Indeed there is no insurance effect.
} 
Proposition 2: Two opposite effects determine the impact of forest productivity on forest cover. A portfolio effect tends to increase forest cover, while an insurance effect tends to reduce it.

Proof: the sign of the first derivative of $R^{*}$ with respect to $\mathrm{f}$ is not determined, and two components can be distinguished (see Appendix A).

First, if the forest is highly productive, its relative profitability compared to forest rises, which tends to increase the forest cover. We call this effect the classic portfolio effect: the share of the risk-free asset - NTFP extraction - in the agent's portfolio is positively correlated with its profitability. Second, if the forest provides a lot of NTFP, less land is needed to insure the household. This insurance effect tends to reduce the forest cover when the forest is more productive, and to increase the most profitable activity. The relative importance of the portfolio and insurance effects depends on risk aversion. A highly risk-averse household will give less importance to the portfolio effect. A rise in forest productivity could come, for example, from a rise in the NTFP prices. A policy frequently advocated to reduce tropical deforestation is the introduction of green labeling for NTFP in order to raise the profitability of the forests. However, in our framework, this positive impact on the forest cover is not straightforward: if the insurance effect dominates, the introduction of green labeling could reduce forest cover.

The two precedent propositions ignore the fact that NTFP extraction from a common property or free access forest can constitute a poverty trap, as an extreme case of a tragedyof-the-commons process. This case is studied in the next section.

\section{Safety-net or poverty trap?}

In this section, we build on Baland and Francois (2005). The share of agricultural land (R) is now supposed to be fixed, and not a choice variable anymore. The choice variable is now the allocation of labor between the two activities. Moreover, the households are supposed to have different productivity on the agricultural land. We distinguish therefore skilled and unskilled households. In contrast to the precedent section and because of household heterogeneity, only unskilled households allocate some labor to CPR extraction. 
The $\mathrm{N}$ households of the community allocate their labor $\left(L_{i}=1\right)$ between two activities. First, labor can be allocated to agricultural exploitation (also called private project). Second, it can be allocated to NTFP (or CPR) extraction. In contrast to Baland and Francois, each household can divide its labor supply and allocate a share in both activities.

We consider a risky agricultural activity with heterogeneous returns, while NTFP extraction provides safe and homogeneous returns. Therefore, NTFP extraction can have two motivations. First, households have different expected returns on their private project and the less skilled households allocate all their labor to CPR extraction, and the CPR returns represent the minimum income of the society (as shown in section 2.1, NTFP extraction requires low skilled labor). Second, the households face also different levels of risk on their private projects and allocate thus a share of their labor supply to CPR extraction in order to insure themselves (note here that no outside insurance possibility is assumed). Whereas Baland and Francois consider separately those two kinds of heterogeneity, the model presented here study the possible poverty-trap implications of the coexistence of these two roles of NTFP extraction: minimum income and insurance.

\subsection{NTFP extraction as insurance and households heterogeneity}

As in Baland and Francois (2005), we assume that all labor allocated to the NTFP extraction is equivalently productive and receives the average product: $\frac{f(L) l_{i}}{L}$, with $l_{i} \in[0,1]$ the amount

of labor allocated to the CPR by household $i$ and $L=\sum_{i=1}^{N} l_{i}$ the total amount of labor allocated to the commons. The commons production function, $f(L)$, is homogeneous of degree 1, strictly increasing and concave in L. Therefore, the average product is decreasing in L, which constitutes a tragedy-of-the-commons effect: labor allocated by a household has a negative externality on the other households. Moreover, the total labor allocated to the commons is an indicator of environmental damages on the forest. Indeed, the overuse of a resource coincides with the degradation of the ecosystem.

As already said, the agricultural activity provides uncertain returns. The expected agricultural return of household $i$ is $E\left(x_{i}\right) \cdot\left(1-l_{i}\right)$, with $E\left(x_{i}\right)$ distributed on $\left[\underline{x_{i}} ; \overline{x_{i}}\right]$. Expected returns, $E(x)$, and minimum returns, $\underline{x}$, constitute a representation of the households heterogeneity in terms of skills and risk, respectively. 
The households are sorted according to the expected return on their private project. Household 1 has the lowest expected return and household $N$ has the highest one.

Household's objective: At the beginning of the period, each household chooses its labor allocation between the two activities, in order to maximize its expected return $\Pi\left(l_{i}\right)$, subject to a minimum consumption requirement:

$$
\begin{aligned}
& \max _{l_{i}} \Pi\left(l_{i}\right)=E\left(x_{i}\right) \cdot\left(1-l_{i}\right)+\frac{f(L)}{L} \cdot l_{i} \\
& \text { s.t } \quad \underline{x_{i}} \cdot\left(1-l_{i}\right)+\frac{f(L)}{L} \cdot l_{i} \geq C_{\text {min }}
\end{aligned}
$$

Indeed each household wants to insure a minimum level of consumption in the worst state of the world. We can think of this minimum level as the subsistence requirement needed to survive. Thus the household is risk neutral, as long as it get its minimum requirement, and is infinitely risk averse under that point. Note that a household not getting more than its subsistence requirement can be considered as poor: it cannot get more from its activities than what it needs to survive.

The minimum amount of labor allocated to the CPR by household $\mathrm{i}$ is thus:

$$
l_{i} \geq \frac{C_{\text {min }}-\underline{x_{i}}}{\frac{f(L)}{L}-\underline{x_{i}}}
$$

Note here that we must have $\frac{f(L)}{L} \geq C_{\min }$ for the insurance property of the CPR to be effective. In fact, if too much labor is allocated to the CPR, the average product go down to its bottom value $C_{\text {min }}$. Therefore, a maximum possible amount of labor in the CPR can be defined. The average product being downward slopping with respect to total labor, the maximum amount of labor in the $\mathrm{CPR}$ is:

$$
L_{\max }: \frac{f\left(L_{\max }\right)}{L_{\max }}=C_{\min }
$$

If too many households are in need of insurance, the insurance capacity of the resource, $L_{\text {max }}$, may be too small. At this point, some households have to migrate and migration occurs until the point at which every remaining household is insured, with the average return being equal to the minimum requirement. Migration is considered here as an action of last resort. Households are therefore assumed to migrate from the area if and only if they cannot get their minimum requirement from their livelihood. 
The equilibrium is a combination of a total amount of labor allocated to the commons, $L_{c}$, a share of labor allocated to the commons by each household, $l_{i}$, and a number of households that have to migrate, $\mathrm{M}$.

At equilibrium, 3 classes of households can be distinguished according to the households allocation of labor.

Unskilled households: The less skilled households have an expected return on the private project smaller or equal to the average product on the CPR. These households allocate all their labor to the CPR. Therefore they get the average product.

$$
\text { For } i \in[1 ; U]:\left\{\begin{array}{l}
E\left(x_{i}\right) \leq \frac{f\left(L_{c}\right)}{L_{c}} \\
l_{i}=1 \\
\Pi\left(l_{i}\right)=\frac{f\left(L_{c}\right)}{L_{c}}
\end{array}\right.
$$

The motivation for CPR extraction here is a lack of better opportunity. Less skilled households rely on this activity because it requires low skilled labor and provides higher returns than agriculture.

Skilled households: The most skilled households are those who get at least their minimum requirement from their private project. Moreover, the expected return on their private project must be greater than the average product on the CPR. Thus they allocate all their labor to the private project. Their expected income is the expected private return.

$$
\text { For } i \in[S+1 ; N]:\left\{\begin{array}{l}
\underline{x_{i}} \geq C_{\text {min }} \\
E\left(x_{i}\right) \geq \frac{f\left(L_{c}\right)}{L_{c}} \\
l_{i}=0 \\
\Pi\left(l_{i}\right)=E\left(x_{i}\right)
\end{array}\right.
$$

This class of household can be considered as "naturally" insured: they always get enough returns from agricultural exploitation to satisfy their basic needs.

Middle class: This last class of household does not appear in Baland and Francois. For this class, agriculture is in expectation more profitable than NTFP extraction. However, there are some states of the world in which this private project does not provide their minimum 
requirement. Therefore they put some labor in NTFP extraction from the CPR in order to insure themselves. Because the expected private project return is greater than the return on CPR extraction, these households allocate labor on the CPR in order to get exactly their minimum requirement in the worst state of the world.

$$
\text { For } i \in[U+1 ; S]:\left\{\begin{array}{l}
E\left(x_{i}\right) \geq \frac{f\left(L_{c}\right)}{L_{c}} \\
\underline{x_{i}} \leq C_{\min } \\
l_{i}=\frac{C_{\min }-\underline{x_{i}}}{\frac{f\left(L_{c}\right)}{L_{c}}-\underline{x_{i}}} \\
\Pi\left(l_{i}\right)=l_{i} \cdot \frac{f\left(L_{c}\right)}{L_{c}}+\left(1-l_{i}\right) \cdot E\left(x_{i}\right)
\end{array}\right.
$$

While in a world with perfect insurance, this class of household would allocate all their labor to the private project and get its expected return, they need here to extract from the CPR in order to insure themselves, at the expense of reducing their expected return.

In order to show how CPR extraction becomes a poverty trap, we need to determine what is the total amount of labor in the CPR.

Total amount of labor allocated to NTFP extraction: Only two classes of household allocate labor to NTFP extraction: the unskilled and the middle class. First, the unskilled households allocate all their labor to the CPR.

$$
\begin{aligned}
& L_{c}^{U}=\sum_{i=1}^{U} 1=U \\
& E\left(x_{U}\right)=\frac{f\left(L_{c}\right)}{L_{c}}
\end{aligned}
$$

Second, the middle-class households allocate only a share of their labor supply to NTFP extraction.

$$
\begin{aligned}
L_{c}^{M} & =\sum_{i=(U+1)}^{S}\left[\frac{C_{\min }-\underline{x_{i}}}{\frac{f\left(L_{c}\right)}{L_{c}}-\underline{x_{i}}}\right] \\
\underline{x}_{(S+1)} & =C_{\min }
\end{aligned}
$$

The total amount of labor allocated to the CPR is:

$$
L_{c}=L_{c}^{U}+L_{c}^{M}
$$

CPR extraction constitute a poverty trap if the equilibrium amount of labor in the commons $L_{c}$ is bigger than $L_{\max }$. Indeed in that case, both poor and middle-class households 
cannot get much than their minimum requirement and are trapped in the CPR extraction activity. Moreover, some households have to migrate until $L_{c}$ equals $L_{\max }$. The population in need to migrate is therefore:

$$
\left\{\begin{array}{l}
M=S-L_{\max }, \text { if } L_{c}>L_{\max } \\
M=0, \text { otherwise }
\end{array}\right.
$$

We restrict here ourselves to the case of common risk, i.e. we define:

$$
\underline{x_{i}}=E\left(x_{i}\right)-C
$$

Where $\mathrm{C}$ is the same across households. At this point, it is possible to describe two types of situation.

\subsection{Tragedy of the commons and poverty trap}

It is well known that an open-access resource suffers of tragedy of the commons: individuals do not take into account the negative externality of their actions on the others. In the case studied here, with CPR used as insurance, this phenomenon can lead to a poverty trap.

Insurance without poverty trap: We consider here the case where: $L_{c} \leq L_{\max }$. Therefore, the insurance use of the CPR does not lead to a poverty trap. Nevertheless, CPR extraction is characterized by a tragedy-of-the-commons process. Note for example that both unskilled and middle class households would be better off with an insurance scheme. Indeed, middle class households could allocate all their labor to their private project, which is more profitable in expectation. Moreover, the unskilled households would be better off too, because the labor supply allocated to the commons would be lower. Therefore, the average product of CPR extraction would be bigger. Figure 5 illustrate this case. 


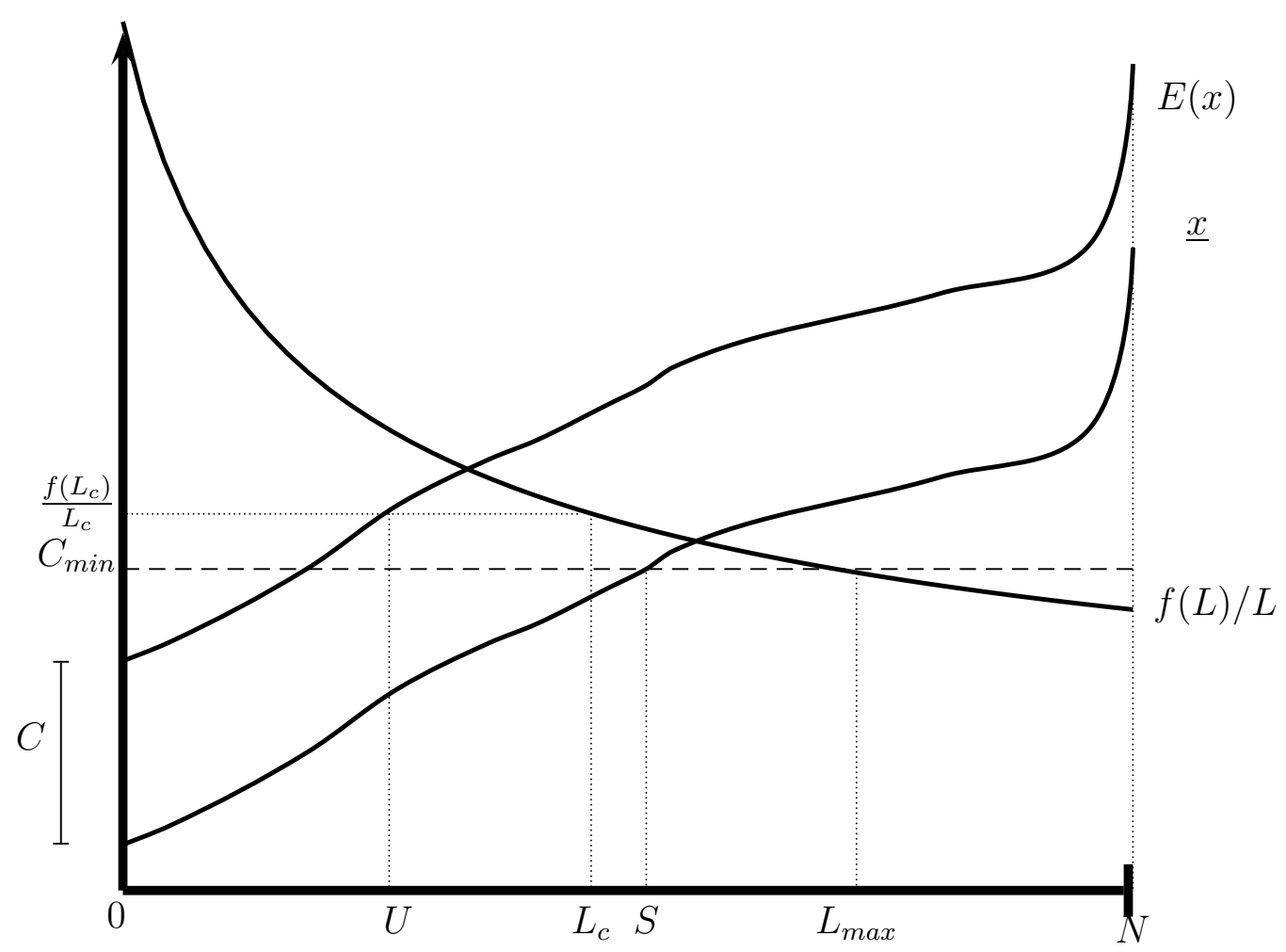

Figure 5: Insurance with no poverty trap and common risk

Insurance with poverty trap The poverty-trap case is a result of: $L_{c} \geq L_{\max }$. More precisely, it is essentially an extreme consequence of the tragedy of the commons described before. As already showed, M households have to migrate until the point at which the average product of $\mathrm{CPR}$ extraction reach the minimum requirement ${ }^{10}$. At this point, however, middle class households have to allocate all their labor to the CPR in order to insure themselves. Therefore, both unskilled and middle class households are perfectly insured but cannot get more than their minimum requirement, which constitute a poverty trap. Figure 2 describes the poverty trap case. Note here that skilled households get the same outcome whatever is the type of situation.

\footnotetext{
${ }^{10} \mathrm{~A}$ potential cause of rural migration in developing countries is therefore considered here.
} 


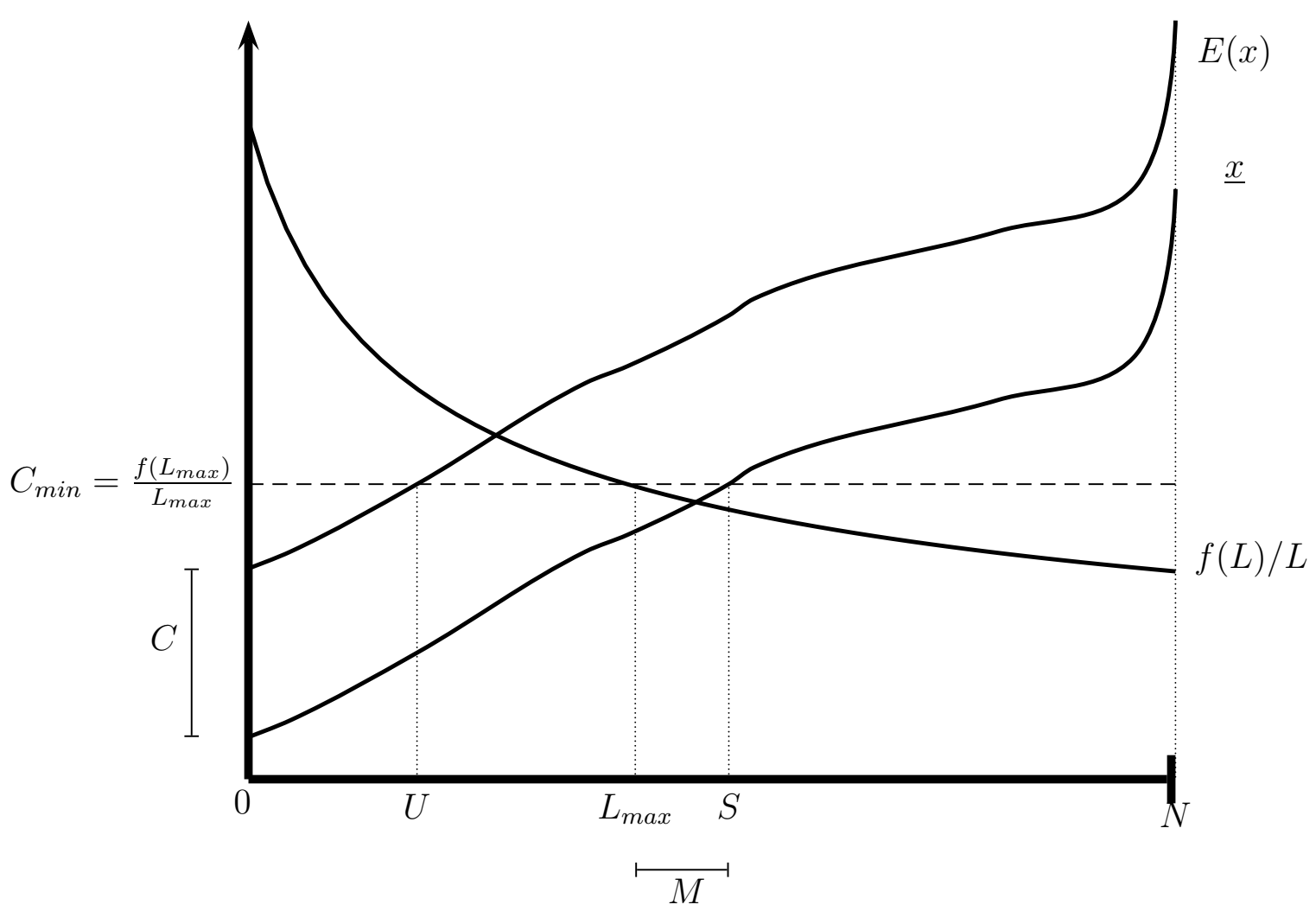

Figure 6: Insurance with poverty trap and common risk

The causes of the poverty trap: A poverty trap is therefore the result of two main factors ${ }^{11}$. First, population factors are important. If the population in need of insurance $(S)$ is big, the poverty trap case is more likely. The size of this population is a consequence of two components: repartition of skills $(E(x))$ and repartition of risk $(\underline{x})$. Firstly, the bigger is the population with relatively high expected return on the private profit, the smaller is the unskilled population. Secondly, the smaller is the risk at which the households are exposed, the bigger is the population that does not depend on the resource.

Second, the production function of the CPR determines the threshold of population $\left(L_{\max }\right)$ that could exploit it. If the environment is fragile, it is quickly saturated and the threshold is low.

Proposition 3 : In a context of risk on agricultural output, the use of NTFP extraction as insurance can lead to a poverty trap if the population in need of insurance is too large

\footnotetext{
${ }^{11} \mathrm{We}$ assume here that the minimum requirement $\left(C_{m i n}\right)$ is the same whatever is the population. We consider here basic needs to survive, such as nutrition.
} 
and the resource has small capacity. Then, both unskilled and middle class households are trapped in NTFP extraction and cannot get more than their basic needs in return.

As already mentioned, the poverty-trap situation is an extreme case of a tragedy of the commons. The only difference in terms of welfare between those two cases is the fact that the middle class totally disappear when CPR extraction becomes a poverty trap. Indeed, the middle class households can insure themselves only at the cost of allocating all their labor to the CPR. They lose therefore all the extra return they could get from agricultural exploitation.

Moreover, as shown in Baland and Francois (2005), privatization may not be a good solution in terms of welfare, since the improved efficiency may not compensate for the reduction of the insurance properties of the CPR.

\section{Conclusion}

This paper aims to investigate the safety-net function of forest products in the economics of land-use change and deforestation. We analyze the trade-off between two land-uses. Agriculture is more profitable but is risky. In contrast, NTFP extraction is less profitable but is used to fill some consumption gaps when agricultural crops are bad. Although quite simple and not considering some important factors such as dynamic effects or labor allocation, the model presented here stresses some important implications. Considering a utility maximizing representative household in a risky environment, the impact of risk reduction, forest productivity and risk aversion on forest cover is addressed.

We predict that a reduction in crop risk may have a negative impact on forest cover. Development policies often consider agricultural development as a priority. Moreover, an important objective is to reduce the risk on poor agricultural households' income. Therefore, to reduce this impact, risk reduction policies should be combined with environmental and forest management policies. For example, payment for environmental services provided by forests may be an interesting tool. Indeed this kind of payment may enforce forest preservation and raise the "profitability" of forests. 
Risk aversion of the household is positively correlated with forest cover, if the bad state of the world is unlikely. This result is quite intuitive, since forest products are a tool to reduce risk. In economic analysis, households are typically more risk averse than entrepreneurs, generally risk neutral. Economic development may raise through market integration the separability between the utility and profit maximizing process. The risk aversion of the household may fall, which could have a negative impact on forest cover.

Moreover, market integration can provide to households new insurance mechanisms, reducing the safety-net use of forest products described in this paper. For example, access to credit markets can help households to compensate for crop shortfalls. This kind of market integration can thus indirectly lead to more deforestation.

Finally, the type of risk management used by the households is important. If NTFP are used only if bad outcomes happen - risk-coping strategy -, the household tends to keep less forest cover than with a risk-diversification strategy. Moreover, a risk-diversification strategy is more welfare improving than a risk-coping strategy, which raises the question about the factors that motivate the use of coping strategies instead of diversification strategies.

However, the potential poverty-trap implications that NTFP extraction can create must be taken into account. If the population in need of insurance is big, and if the forest capacity is small, a tragedy-of-the-commons process can trap the less skilled households into NTFP extraction and deprive them of other development opportunities.

Agricultural risk and the safety-net use of NTFP extraction is therefore an crucial issue with important economic and environmental implications such as deforestation, poverty-trap and degradation of commonly-held forests. Some empirical analysis of the relationships that link agricultural risk, poverty and deforestation could give interesting indications. Moreover a related issue is the study of potential conflicts of interest between local communities using the resource and forest loggers. In this context, corruption and lobbying powers have an important role, that could lead, for the local communities, to the deprivation of the resource.

\section{Acknowledgements}

I thank my supervisor, Rick van der Ploeg, for his helpful advice. I also acknowledge useful comments from Arild Angelsen and Pascal Courty. An earlier version of this paper was pre- 
sented at a CERDI seminar, Université d'Auvergne, June 2004, where participants provided valuable comments. I am grateful to the Lavoisier programme for financial support.

Paper to be presented to the "14th Annual Conference of the European Association of Environmental and Resource Economists" (Bremen, June 2005) and to the EAERE - FEEM - VIU Summer School in Environmental Economics (Venice, July 2005). 


\section{Appendix A: comparative statics}

Proof of proposition 1: assuming the fixed labor constraint is not binding, we take the first derivatives of the optimal share of agricultural land $R^{*}$ with respect to our variables of interest.

$$
\begin{aligned}
& \frac{\partial R^{*}}{\partial \underline{x}} \cdot d \underline{x}+\frac{\partial R^{*}}{\partial \bar{x}} \cdot d \bar{x}=\frac{N\left[\frac{d \underline{x}}{(f-\underline{x})}+\frac{d \bar{x}}{\bar{x}}\right]}{\alpha(\bar{x}-\underline{x}+f)}+\frac{\left[f+\frac{N}{\alpha}\left[\ln \frac{\delta \bar{x}}{(1-\delta)(f-\underline{x})}\right]\right][d \underline{x}-d \bar{x}]}{(\bar{x}-\underline{x}+f)^{2}} \\
& \frac{\partial R^{*}}{\partial \alpha}=\frac{-N \ln \left[\frac{\delta \bar{x}}{(1-\delta)(f-\underline{x})}\right]}{\alpha^{2}[\bar{x}-\underline{x}+f]}<0 \quad \text { if } \delta>\frac{f-\underline{x}}{\bar{x}-\underline{x}+f} \\
& \frac{\partial R^{*}}{\partial N}=\frac{\ln \left[\frac{\delta \bar{x}}{(1-\delta)(f-\underline{x})}\right]}{\alpha[\bar{x}-\underline{x}+f]}>0 \quad \text { if } \delta>\frac{f-\underline{x}}{\bar{x}-\underline{x}+f}
\end{aligned}
$$

With $\delta=0.5$ :

$$
\begin{aligned}
\frac{\partial R^{*}}{\partial \underline{x}}-\frac{\partial R^{*}}{\partial \bar{x}} & =\frac{2 f+\frac{N}{\alpha}\left[2 \ln \left[\frac{\bar{x}}{(f-\underline{x})}\right]+\frac{(\bar{x}-\underline{x}+f)(\bar{x}+\underline{x}-f)}{(f-\underline{x}) \bar{x}}\right]}{(\bar{x}-\underline{x}+f)^{2}}>0 \\
\frac{\partial R^{*}}{\partial \alpha} & =\frac{-N \ln \left[\frac{\bar{x}}{(f-\underline{x})}\right]}{\alpha^{2}[\bar{x}-\underline{x}+f]}<0 \\
\frac{\partial R^{*}}{\partial N} & =\frac{\ln \left[\frac{\bar{x}}{\left(\frac{f-\underline{x}}{)}\right]}\right.}{\alpha[\bar{x}-\underline{x}+f]}>0
\end{aligned}
$$

Proof of proposition 2: the sign of the derivative of $R^{*}$ with respect to $\mathrm{f}$ is not determined.

$$
\frac{\partial R^{*}}{\partial f}=\frac{\bar{x}-\underline{x}-\frac{N}{\alpha}\left[1+\frac{\bar{x}}{f-\underline{x}}+\ln \left[\frac{\delta \bar{x}}{(1-\delta)(f-\underline{x})}\right]\right]}{(\bar{x}-\underline{x}+f)^{2}}
$$

However, two opposite effects can be distinguished. First, the insurance effect pushes up the agricultural share and depends on the gap between agricultural productivity in the two states $(\bar{x}-\underline{x})$. Second, the portfolio effect tends to increase the forest cover and depends on the relative productivity of forests compared to agriculture in the two states of the world $\left(1+\frac{\bar{x}}{f-\underline{x}}+\ln \left[\frac{\delta \bar{x}}{(1-\delta)(f-\underline{x})}\right]\right)$. Note that the portfolio effect is decreasing in risk aversion $\alpha$. 


\section{Appendix B: NTFP as a risk-diversification strategy}

This appendix aims to stress the differences between the coping and the diversification strategies. The only difference to the coping strategy is the possible use of NTFP in all the states of the world. All the changes in the results come from this difference.

\section{B-1 Changes in the main model results}

$$
\begin{aligned}
E(f) & =f \\
R^{*} & =\frac{N C^{m i n}-f}{E(x)-f} \\
\bar{C} & =\frac{1}{N}[R \bar{x}+(1-R) f] \\
\underline{C} & =\frac{1}{N}[R \underline{x}+(1-R) f] \\
E_{c}(R) & =\frac{1}{N}[R(E(x)-f)+f] \\
\sigma_{c}^{2} & =\frac{1}{N^{2}} \sigma_{x}^{2} R^{2} \\
R^{*} & =\left(\frac{N\left[\ln \frac{\delta(\bar{x}-f)}{(1-\delta)(f-\underline{x})}\right]}{\alpha(\bar{x}-\underline{x})}\right)
\end{aligned}
$$

\section{B-2 Comparative statics}

The sign of the first derivative of $R^{*}$ with respect to the variables of interest gives us the impact of a change in variables. In contrast to the coping strategy, the impact on $R$ of a raise in risk aversion (resp. population) is always negative (resp. positive) with the diversification strategy.

$$
\begin{aligned}
\frac{\partial R^{*}}{\partial \underline{x}} \cdot d \underline{x}+\frac{\partial R^{*}}{\partial \bar{x}} \cdot d \bar{x} & =\left(\frac{N}{\alpha(\bar{x}-\underline{x})}\right)\left[\frac{d \underline{x}}{(f-\underline{x})}+\frac{d \bar{x}}{(\bar{x}-f)}+\left(\ln \frac{\delta(\bar{x}-f)}{(1-\delta)(f-\underline{x})}\right) \frac{(d \underline{x}-d \bar{x})}{(\bar{x}-\underline{x})}(40)\right. \\
\frac{\partial R^{*}}{\partial \alpha} & =\frac{-N \ln \left[\frac{\delta(\bar{x}-f)}{(1-\delta)(f-\underline{x})}\right]}{\alpha^{2}[\bar{x}-\underline{x}]}<0 \\
\frac{\partial R^{*}}{\partial N} & =\frac{\ln \left[\frac{\delta(\bar{x}-f)}{(1-\delta)(f-\underline{x})}\right]}{\alpha[\bar{x}-\underline{x}]}>0
\end{aligned}
$$


With $\delta=0.5$ :

$$
\frac{\partial R^{*}}{\partial \underline{x}}-\frac{\partial R^{*}}{\partial \bar{x}}=\left(\frac{N}{\alpha(\bar{x}-\underline{x})}\right)\left[\frac{1}{(f-\underline{x})}-\frac{1}{(\bar{x}-f)}+2 \ln \frac{(\bar{x}-f)}{(f-\underline{x})}\right]>0
$$

Moreover, there is no insurance effect, and forest productivity always has a positive impact on the forest cover.

$$
\frac{\partial R^{*}}{\partial f}=\frac{N}{\alpha(\bar{x}-\underline{x})}\left[\frac{-1}{(\bar{x}-f)}-\frac{1}{(f-\underline{x})}\right]<0
$$

\section{Appendix C: parameter values of figure 1-4}

Table 2:

\begin{tabular}{|c|c|c|c|}
\hline Variable & Symbol & Initial value & Adapted value \\
\hline Total land area & $\mathrm{H}$ & 1932 & 1 \\
Number of households & $\mathrm{N}$ & 82 & 0.042 \\
Expected output in agriculture & $E(x)$ & 500 & 0.26 \\
Low level of output & $\underline{x}$ & n.a & 0.15 \\
High level of output & $\bar{x}$ & n.a & 0.37 \\
Forest products intensity & $\mathrm{f}$ & n.a & 0.22 \\
Probability of $\bar{x}$ & $\delta$ & n.a & 0.5 \\
Absolute Risk Aversion coefficient & $\alpha$ & n.a & 0.5 \\
\hline
\end{tabular}

n.a: not available

Source: Angelsen (1995, 1999) 


\section{References}

[1] H. Aldermann and C. Paxson. Do the poor insure? A synthesis of the litterature on risk and consumption in developing countries, volume 4. Economics in a changing world, London, mcmillan edition, 1994.

[2] A. Angelsen. Shifting cultivation and deforestation: A study from indonesia. World Development, 23(10), 1995.

[3] A. Angelsen. Agricultural expansion and deforestation: Modelling the impact of population, market forces and property rights. Journal of Development Economics, 58:185-218, 1999.

[4] A. Angelsen and S. Wunder. Exploring the forest-poverty link. CIFOR Occasional Paper n40, (2002).

[5] J.M Baland and P. Francois. Commons as insurance and teh welfare impact of privatization. Journal of Public Economics, 2004. Article In Press.

[6] World Bank. A revised forest strategy for the world bank group. Technical report, World Bank, Washington D.C., Draft 30 July 2001.

[7] E. Barbier. Links between economic liberalization and rural resource degradation in the developing countries. Agricultural Economics, 23:299-310, 2000.

[8] R. Bluffstone. The effect of labor market performance on deforestation in developping countries under open access: An example from rural nepal. Journal of Environmental Economics and Management, 29:42-63, 1995.

[9] D.W. Bromley and J.P. Chavas. On risk, transactions and economic development in the semiarid tropics. Economic Development and Cultural Change, pages 719-736, 1989.

[10] N. Byron and M. Arnold. What future for the people of the tropical forests? CIFOR Working Paper n19, 1997.

[11] M. Das Gupta and K.G. Maler. Handbook of development economics, volume 3, chapter Poverty and the Environmental Resource Base. University of Cambridge, 1993. 
[12] S. Dercon. Income risk, coping strategies and safety nets. The World Bank Research Observer, 17(2):141-166, 2002.

[13] FAO. Forest resources assessment, tropical countries. Technical report, FAO, Rome; FAO, 1992. Forestry Paper n112.

[14] FAO. State of the world forests. Technical report, FAO, Rome; FAO, 1997.

[15] C. Gollier. The economics of risk and time. MIT Press, Cambridge, Mass., 2001.

[16] G. Hardin. The tragedy of the commons. Science, 162:1243-48, 1968.

[17] J. Hartwick, N. Van Long, and H. Tian. Deforestation and development in a small open economy. Journal of Environmental Economics and Management, 41:235-251, 2001.

[18] D. Kaimowitz and A. Angelsen. Economic models of tropical deforestation: a review. CIFOR, www.cgiar.org/cifor, 1998.

[19] D. Kaimowitz and A. Angelsen. Rethinking the causes of deforestation: Lessons from economic models. The World Bank Research Observer, 14(1), 1999.

[20] S. Kumar. Does participation in common pool resource management help the poor? a social cost-benefit analysis of joint forest management in jharkland, india. World Development, 30(5):763-782, 2002.

[21] R. Lopez. Structural models of the farm household that allow for interdependent utility and profit-maximisation decisions, chapter 11. Johns Hopkins University Press, Baltimore, MD, 1986.

[22] R. Lopez. Agricultural intensification, common property resources and the farmhousehold. Environmental and Resource Economics, 11(3-4), 1998.

[23] N. Myer. Tropical forests; the policy challenge. Environmentalist, 12(1), 1992.

[24] R.P Neumann and E. Hirsch. Commercialisation of non-timber forest products: a review. Technical report, CIFOR, Bogor, Indonesia and FAO, Rome, 2000. 
[25] P. Parks, E. Barbie, and J. Burgess. The economics of forest land use in temperate and tropical areas. Environmental and Resource Economics, 11(3-4), 1998.

[26] S.K Pattanayak and E.O Sills. Do tropical forests provide natural insurance? the microeconommics of non-timber forest product collection in the brazilian amazon. Land Economics, 77(4):595-612, 2001.

[27] T. Reardon, C. Barret, V. Kelly, and K. Savadogo. Policy reforms and sustainable agricultural intensification in africa. Development policy review, 17:293-313, 1999.

[28] S.R.C Reddy and S.P Chakravaty. Forest dependence and income distribution in a subsistence economy. World Development, 27(7):1141-1149, 1999.

[29] R. Repetto and M. Gillis, editors. Public Policies and the Misuse of Forest Resources. Cambridge University Press, 1988.

[30] M. Ros-Tonen and F Wiersum. The importance of non-timber forest products for forestbased rural livelihoods: an evolving research agenda. 2003. AGIDS.

[31] B. Shiferaw and S. Holden. Policy instruments for sustainable land management: The case of highland smallholders in ethiopia. Agricultural Economics, 22:217-232, 2000.

[32] B. Shiferaw and S. Holden. Land degradation, drought and food security in a lessfavoured area in the ethiopian highlands: a bio-economic model with market imperfections. Agricultural Economics, 30:31-49, 2004.

[33] I. Singh, L. Squire, and J. Strauss, editors. Agricultural household models: Extensions, Applications and Policy. Johns Hopkins University Press, Baltimore, MD, 1986.

[34] M. Smouts. La deforestation au xxème siècle. Cahiers Français, 306, 2002.

[35] W. Sunderlin, A. Angelsen, D. Ahmad Dermawan, and E. Rianto. Economic crisis, small farmer well-being, and forest cover change in indonesia. World Development, $29(5), 2001$.

[36] O. Sydorovych. Economics of the forest land use in developing countries a brief literature survey. 2001. North Carolina State University. 
[37] E. Taylor and I. Adelman. Agricultural household models: Genesis, evolution, and extensions. Review of Economics of the Households, 1(1), 2003.

[38] J. Torkamani and M. Haji-Rahimi. Evaluation of farmer's risk attitudes using alternatives utility functional forms. Journal of Agricultural Science and Techonology, 3:243$248,2001$.

[39] UNEP. Geo 2003. chapitre 2: Les forets. Technical report, UNEP, www.unep.org, 2003.

[40] S. Vosti, E. Munoz Braz, C. Carpentier, M. D’Oliveira, and J. Witcover. Rights to forest products, deforestation and smallholder income: Evidence from the western brazilian amazon. World Development, 31(11), 2003.

[41] E. Wollenberg and A. Ingles. Incomes from the forest. methods for the development and conservation of forest products for local communities. Technical report, CIFOR, Bogor, Indonesia, 1998.

[42] S. Wunder. Poverty alleviation and tropical forests. what scope for synergies? World Development, 29(11), 2001. 